\title{
Inclusive mathematics education
}

\section{Ann Gervasoni ${ }^{1} \cdot$ Andrea Peter-Koop $^{2}$}

Published online: 21 February 2020

(C) The Author(s) 2020

In 2008, the Australian Government, in common with many other countries, ratified the Convention on the Rights of Persons with a Disability (CRPD) and has since voiced its commitment to inclusive education in key documents and policies. While achieving genuine inclusive education is a pressing moral, political and humanitarian imperative, internationally, there is little published research with respect to the question of how to realise inclusive mathematics educations in schools. In the meantime, teachers at all levels struggle to meet the challenge of providing a high-quality inclusive mathematics education that enables all students to thrive.

This MERJ Special Issue on Inclusive Mathematics Education publishes new international research and scholarship to better illuminate this field of research, with a focus on highlighting teaching approaches and curricula that enable mathematics learning for all children in inclusive settings.

As editors of this Special Issue, our goal was to reflect the breadth and diversity of the topic with respect to methodological approaches, curricula and international contexts when inviting and selecting the contributing authors from seven different countries and four continents. We were guided by a broad understanding of inclusion that is not limited to students with disabilities but considers learners with diverse abilities and special rights for learning mathematics. We also wanted to pay tribute and attention to teachers and their work towards developing practices that include all learners in genuine opportunities to learn mathematics.

In providing an overview of the contributions to this Special Issue, we begin with Rachel Lambert (University of California) and Paulo Tan (University of Hawai'i) who present a systematic review of international research on the teaching and learning of mathematics from pre-kindergarten to year 12, using a Disability Studies in Education

We dedicate this Special Issue to our friend and colleague Professor David Clarke for whom the better understanding and improvement of mathematics teaching and learning in classrooms all over the world was a lifelong mission. David's contributions to the development of mathematics education in Australia and beyond are invaluable.

Andrea Peter-Koop

andrea.peter-koop@uni-bielefeld.de

1 Monash University, Melbourne, Australia

2 Bielefeld University, Bielefeld, Germany 
framework. Analysing 2477 research articles, they found that research concerning students with disabilities was predominantly quantitative and tended to draw on behavioural and medical theoretical orientations. In contrast, research concerning students without disabilities was more equally spread with respect to both quantitative and qualitative approaches, and tended to use constructivist and sociocultural theoretical foundations. The two authors argue that these differences in research orientations contribute to the segregation of students with disabilities and lowachieving students, and to lower quality mathematics instruction, and may lead to low expectations of the mathematical competence of students with disabilities. They call for more research that "considers how disability is produced and enacted in the complex content of mathematics education".

Jodie Hunter, Roberta Hunter and Glenda Anthony (Massey University, New Zealand) take on this issue through their approach to shift towards equity in mathematics education. They closely examine the use of ability grouping in classrooms and related research studies that highlight the negative effects and lack of opportunities for students who are placed in low-ability groups. Their professional development project Developing Mathematical Inquiry Communities (DMIC) seeks to support more inclusive and equitable pedagogy in mathematics classrooms. They report on changes in teachers' beliefs about ability grouping over time as they redevelop their pedagogical practices as part of their participation in the project. The authors use Valsiner's zone theory to explain how the changed classroom practices supported more equitable approaches to teaching and learning.

The article by Lena Lindenskov (Aarhus University, Denmark) and Bent Lindhardt (University College Absalon in Roskilde, Denmark) provides insights into a project that sought to foster inclusive mathematics education in regular classrooms in ordinary schools. The MINK (Mathematics and Inclusion) project started as a reaction to challenges for inclusive practices arising from political reform in Denmark. The basis of the paper is a design study involving classroom experiments and teacher professional learning for grade 4 and grade 5 teachers and students. The authors present and discuss themes that emerged during MINK with respect to classroom challenges and practices that promoted inclusive mathematics education. They also reflect on how the insights gained from the study might inform ongoing professional learning for mathematics teachers.

Sally-Ann Robertson and Mellony Graven from Rhodes University in South Africa focus on the issue of language as an including or excluding factor in mathematics teaching and learning. Their paper focusses on the situation in South Africa (which is typical of many other countries around the globe), where English is chosen as the language of instruction in primary school, because English is perceived as "the language of opportunity". They argue that the consequence of this decision is the low performance of students at all levels in (inter-)national assessment studies. Based on their review of the research concerning language immersion education models and their alignment with key principles of second language acquisition, they present and analyse empirical data from two grade 4 classrooms to illuminate the challenges students and teachers face in their mathematical sense-making.

While, from our point of view, it is important to apply a broad understanding of inclusion that is not limited to learners with disabilities, as demonstrated in these first four articles, we do not neglect the importance of qualitative and quantitative research 
in this field. Hence, the final three articles focus on the scientific analyses of the special needs of students with diverse intellectual and physical abilities.

In order to improve inclusive classroom practice, it is important to better understand the needs of children with intellectual disabilities (ID) and how these needs can be met in inclusive mathematics classrooms. Current research suggests that inclusive education has a positive influence on the development of language skills for this group of students, while there is hardly any evidence about the impact on mathematics learning for this group. In this context, the Swiss researchers Susanne Schnepel, Helena Krähenmann, Elisabeth Moser Opitz (University of Zurich) and Rachel Sermier Dessemontet (School of Education Vaud, Lausanne) conducted a longitudinal study investigating the potential learning gains of students with ID in grade 2 and grade 3 in inclusive mathematics classrooms. The basis for their research was whether these students "are restricted in their learning because of their intellectual constraints or because of insufficient or inappropriate support". The findings from their cluster analysis suggest that learners with ID had variable needs which made inclusive instruction extremely challenging for their teachers who were trying to integrate the selection of appropriate activities, materials, and the differentiation of learning goals, with learning situations and collaborative settings that are important for social inclusion.

The contribution by Rhonda Faragher (The University of Queensland, Brisbane) and Barbara Clarke (Monash University, Melbourne) takes this notion further as they explore inclusive practices for children with Down syndrome. They start their paper with the claim that "children with Down syndrome can and do learn important mathematics, and that increasingly this occurs in regular school classrooms". The two authors then present findings from a qualitative study that followed 16 teachers and their learning support assistants over a whole school year while they were teaching mathematics for a class that included a child with Down syndrome. Vignettes illustrate the adjustments the teaching teams made with respect to implementation and planning and provide insights into the related teacher decision-making process. One interesting finding was that the adjustments made to activities and materials for the learners with Down syndrome also supported the mathematics learning of other children in the class. Their detailed study of teachers' practices has high potential for the development of effective inclusive instruction.

Finally, the German authors Thomas Rottmann (Bielefeld University), Nora Haberzettl (Studienseminar Kassel/Eschwege) and Magali Krämer (Betty-HirschSchool for students with visual impairments, Stuttgart) present their work on the adaptation of a mathematics assessment tool based on a German version of the Victorian Mathematics Online Interview (https://www.education.vic.gov. $\mathrm{au} / \mathrm{school} /$ teachers/teachingresources/discipline/maths/assessment/Pages/mathsassess. aspx) for children with varying degrees of visual impairments, including case study data from the trial. In addition to the growth point framework used in the MOI and its German equivalent, they designed a more detailed competence grid to facilitate indepth analysis of individual children's learning and understanding. This has great potential to support inclusive mathematics education for this group of children, who are often neglected in mathematics education research.

We hope that the seven papers in this Special Issue help to illustrate the vast scope of the research that is necessary to better understand the issues and effective practices 
involved in providing ambitious and equitable inclusive mathematics education. The authors are active experts in this field, and we anticipate that their scholarship will inform both policy and curriculum development, as well as classroom practices that promote and foster inclusive mathematics education in the coming decade.

Funding Information Open Access funding provided by Projekt DEAL.

Open Access This article is licensed under a Creative Commons Attribution 4.0 International License, which permits use, sharing, adaptation, distribution and reproduction in any medium or format, as long as you give appropriate credit to the original author(s) and the source, provide a link to the Creative Commons licence, and indicate if changes were made. The images or other third party material in this article are included in the article's Creative Commons licence, unless indicated otherwise in a credit line to the material. If material is not included in the article's Creative Commons licence and your intended use is not permitted by statutory regulation or exceeds the permitted use, you will need to obtain permission directly from the copyright holder. To view a copy of this licence, visit http://creativecommons.org/licenses/by/4.0/. 